А. П. Анисимов*,
А. С. Мограбян** Договор о суррогатном материнстве
в России и зарубежных странах

Аннотация. На основе анализа норм российского и зарубежного законодательства выявлены основные проблемы правового регулирования отношений в сфере суррогатного материнства. Рассмотрены вопросы теории и места договора суррогатного материнства в системе гражданско-правовых обязательств. Проведен анализ зарубежного опыта правового регулирования в исследуемой сфере. Особое внимание уделено белорусскому опыту регулирования вспомогательных репродуктивных технологий, который представляет интерес для отечественного законодательства. Даны конкретные рекомендации по совершенствованию российского законодательства в сфере суррогатного материнства с целью предотвращения споров относительно происхождения ребенка или детей, рожденных женщиной, которая вынашивала плод после переноса донорского эмбриона. Сделан вывод о необходимости установления на законодательном уровне ограничений немедицинского характера для суррогатной матери. Даны рекомендации по усилению механизма гарантий прав добросовестных сторон договора о суррогатном материнстве. Обоснована целесообразность установления предельного числа осуществления женщиной функции суррогатной матери.

Ключевые слова: договор; гражданско-правовое обязательство; семейное правоотношение; возмездное оказание услуг; суррогатное материнство; суррогатная мать; генетическая мать; генетические родители; эмбрион; ребенок; дети; вспомогательные репродуктивные технологии; экстракорпоральное оплодотворение. Для цитирования: Анисимов А. П., Мограбян А. С. Договор о суррогатном материнстве в России и зарубежных странах // Актуальные проблемы российского права. - 2020. - T. 15. - № 5. - С. 117-125. - DOI: 10.17803/1994-1471.2020.114.5.117-125.

(C) Анисимов А. П., Мограбян А. С., 2020

* Анисимов Алексей Павлович, доктор юридических наук, профессор, профессор кафедры гражданского права и процесса Калмыцкого государственного университета ул. Пушкина, д. 11, г. Элиста, Республика Калмыкия, Россия, 358000 anisimovap@mail.ru

** Мограбян Армине Самвеловна, кандидат юридических наук, доцент кафедры гражданско-правовых дисциплин Волгоградского института управления - филиала Российской академии народного хозяйства и государственной службы при Президенте РФ ул. Гагарина, д. 8, г. Волгоград, Россия, 400005 rtif@inbox.ru 


\title{
Surrogacy Agreement in Russia and Foreign Countries
}

\author{
Aleksey P. Anisimov, Dr. Sci. (Law), Professor, Professor of the Department of Civil Law and \\ Procedure, Kalmyk State University \\ ul. Pushkina, d. 11, Elista, Republic of Kalmykia, Russia, 358000 \\ anisimovap@mail.ru \\ Armine S. Mograbyan, Cand. Sci. (Law), Associate Professor of the Department of Civil Law \\ Disciplines, Volgograd Institute of Management (Branch of the Russian Presidential Academy \\ of National Economy and Public Administration) \\ ul. Gagarina, d. 8, Volgograd, Russia, 400005 \\ rtif@inbox.ru
}

\begin{abstract}
Based on the analysis of the norms of Russian and foreign legislation, the main issues of legal regulation of relations in the field of surrogate motherhood are identified. The questions of the theory and place of the surrogate motherhood agreement in the system of civil law obligations are considered. The author conducts an analysis of foreign experience in legal regulation in the studied area. The Belarusian experience in assisted reproductive technologies regulation, which is of interest to domestic legislation, is given particular attention. The paper provides concrete recommendations on improving Russian legislation in the field of surrogacy in order to prevent disputes regarding the origin of the child or children born to a woman who was bearing a fetus after transferring a donor embryo. The author concludes that it is necessary to establish, at the legislative level, non-medical restrictions for a surrogate mother. Recommendations on strengthening the mechanism for guaranteeing the rights of bona fide parties to a surrogate motherhood agreement are given. The expediency of establishing the maximum number of a woman to exercise the function of a surrogate mother is substantiated.

Keywords: contract; civil liability; family relationship; paid services; surrogacy; surrogate mother; genetic mother; genetic parents; embryo; child; children; assisted reproductive technologies; in vitro fertilization.

Cite as: Anisimov AP, Mograbyan AS. Dogovor o surrogatnom materinstve v Rossii i zarubezhnykh stranakh [Surrogacy Agreement in Russia and Foreign Countries]. Aktualnye problemy rossiyskogo prava. 2020;15(5):117125. DOI: 10.17803/1994-1471.2020.114.5.117-125. (In Russ., abstract in Eng.).
\end{abstract}

$\mathrm{B}$ конце 70-х гг. XX в. количество бесплодных пар в мире составляло 5 \%. В настоящий момент их число выросло до 10-15 \%, а по некоторым данным, их количество доходит до 30 \%. Между тем цифра 15 \% уже является свидетельством государственного значения этой проблемы ${ }^{1}$.

Современные медицинские технологии для лечения бесплодия предполагают использование таких методов терапии, при которых зачатие и раннее развитие эмбрионов происходит вне организма женщины (вспомогательные репродуктивные технологии). К ним следует отнести и суррогатное материнство, которое основано на экстракорпоральном оплодотворении, представляющем собой процесс зачатия вне тела человека и последующий перенос оплодотворенной яйцеклетки в матку другой женщины, являющейся суррогатной матерью.

Легальное определение суррогатного материнства дается в ч. 9 ст. 55 Федерального закона от 21.11.2011 № 323-Ф3 (в ред. от 29. 05.2019) «Об основах охраны здоровья граждан в Российской Федерации»². Суррогатное материнство представляет собой вынашивание и рождение ребенка (в том числе преждевременные роды) по договору, заключаемому между суррогатной матерью (женщиной, вынашивающей плод после пере-

1 Малиновская Е. Г. Правовое регулирование суррогатного материнства в Российской Федерации и в Республике Беларусь // Семейное и жилищное право. 2007. № 2. С. 29.

2 С3 РФ. 2011. № 48. СТ. 6724. 
носа донорского эмбриона) и потенциальными родителями, чьи половые клетки использовались для оплодотворения, либо одинокой женщиной, для которых вынашивание и рождение ребенка невозможно по медицинским показаниям.

Данный метод искусственного оплодотворения впервые был применен в Великобритании (1978 г.), а первый ребенок, полноценно выношенный суррогатной матерью, появился на свет в США в 1986 г. Вскоре после массового применения данного метода выяснилось, что эта медицинская проблема имеет ряд серьезных правовых, политических, этических и иных аспектов.

В большинстве зарубежных стран суррогатное материнство запрещено законом (Австрия, Германия, Франция, Швеция, некоторые штаты США). В некоторых странах его применение ограничено. Так, например, в Австралии, Великобритании, Венгрии, Израиле, Канаде и ряде иных стран законодательное разрешение получило лишь некоммерческое суррогатное материнство. В других странах, в том числе и в некоторых странах Восточной Европы, помимо некоммерческого суррогатного материнства разрешено и коммерческое (Россия, Украина, Казахстан, ЮАР, некоторые штаты США). В третьей группе стран (Бельгия, Греция, Ирландия) суррогатное материнство имеет место, но законодательно никак не регулируется ${ }^{3}$.

Отношения в сфере суррогатного материнства оформляются договором. В настоящий момент в юридической науке идет дискуссия о природе такого договора. Одни авторы (например, Т. В. Краснова) считают, что справедливо говорить о гражданско-правовой природе договора о суррогатном материнстве, поскольку анализ се- мейного законодательства позволяет заключить, что в качестве участников отношений, урегулированных нормами семейного права, суррогатная мать не упоминается, а конструкция такого договора может быть основана на положениях ГК РФ о договоре возмездного оказания услуг ${ }^{4}$. Другие авторы (например, С. Ю. Чашкова) полагают, что, несмотря на гражданско-правовую природу, договоры о суррогатном материнстве следует относить и к сфере семейно-правового регулирования и справедливо говорить о том, что они находятся на границе гражданского и семейного права ${ }^{5}$. Сторонником особых «семейно-правовых» договоров (правда, применительно к брачному договору) является Н. Ф. Звенигородскаяб.

Договор суррогатного материнства во многом похож по признакам на договор возмездного оказания услуг, но между ними имеется и ряд различий. В частности, по российскому законодательству договор суррогатного материнства может осуществляться как на возмездной, так и на безвозмездной основе, что нехарактерно для договора возмездного оказания услуг и исключает возможность его отнесения к подвидам последнего ${ }^{7}$.

Как отмечает Е. С. Митрякова, «законодателю следует принять во внимание бесспорное сходство договора суррогатного материнства с договором возмездного оказания услуг и включить его в перечень договоров, на которые распространяется действие гл. 39 Гражданского кодекса РФ... несмотря на то, что иногда данный договор бывает безвозмездным, в большинстве случаев он носит возмездный характер и, соответственно, имеет признаки договора возмездного оказания услуг» ${ }^{8}$. Следует согласиться

3 Борисова Т. Е. Суррогатное материнство в РФ: проблемы теории и практики : монография. М., 2012.

4 Краснова Т. В. Основания возникновения семейных правоотношений // Современное состояние российского законодательства: проблемы и пути совершенствования : тезисы докладов междунар. науч.-практ. конференции (г. Пермь, 23 октября 2009 г.). Пермь, 2009. С. 264.

5 Чашкова С. Ю. Система договорных обязательств в российском семейном праве : автореф. дис. .... канд. юрид. наук. М., 2004. С. 21-23.

6 Звенигородская Н. Ф. Семейно-правовые сделки: проблемы классификации // Вестник Омского университета. Серия : Право. 2011. № 4. С. 79-87.

7 Борисова Т. Е. Указ. соч.

8 Митрякова Е. С. Правовое регулирование суррогатного материнства в России : дис. ... канд. юрид. наук. Тюмень, 2007. С. 81. 
с Т. Е. Борисовой в том, что неверно часть договоров суррогатного материнства относить к договорам возмездного оказания услуг, а другую часть оставлять без внимания. Целесообразно выделение договора суррогатного материнства в самостоятельный вид договора 9 .

На наш взгляд, трудно согласиться с выделением особых "семейно-правовых сделок», хотя специфика семейных отношений не вызывает сомнений. Однако если мы пойдем по этому пути, то нам придется признать и специфику земельно-правовых сделок (договор об установлении земельного сервитута, договор безвозмездного пользования служебным наделом и т.д.). Кроме того, подобные особенности существуют и в ряде других отраслей права. На наш взгляд, более правильным все же будет подход, согласно которому в случае с договором суррогатного материнства мы имеем сложное обязательство, включающее в себя классический гражданско-правовой договор и личное неимущественное обязательство суррогатной матери по передаче ребенка генетическим родителям. Теоретическая конструкция сложных обязательств является на сегодняшний день мало разработанной в российской юридической науке, хотя первые шаги уже сделаны ${ }^{10}$.

Сторонами договора суррогатного материнства по российскому законодательству являются: суррогатная мать; потенциальные родители или одинокая женщина. В юридической науке существуют различные точки зрения относительно сторон договора суррогатного материнства. Ряд авторов считают этот договор многосторонним ${ }^{11}$. В частности, А. Н. Чаплыгин полагает, что третьей стороной по договору суррогатного материнства должно являться прово- дящее медицинское вмешательство лечебное учреждение ${ }^{12}$.

Однако, как справедливо отмечает Т. Е. Борисова, такой подход не соответствует принципиальным положениям семейного права, которое регулирует отношения физических лиц - членов семьи ${ }^{13}$.

Исходя из анализа норм российского законодательства, регулирующих институт суррогатного материнства, можно заключить, что заказчиками по договору суррогатного материнства могут выступать как супруги, состоящие в зарегистрированном в установленном порядке браке, так и пара, не состоящая в браке, а также одинокая женщина. Обязательными условиями для заключения договора суррогатного материнства, которым должны соответствовать потенциальные родители, являются: наличие информированного добровольного согласия на медицинское вмешательство, использование их половых клеток для оплодотворения и невозможность вынашивания и рождения ребенка по медицинским показаниям, перечень которых приводится в п. 79 приказа Минздрава России от 30.08.2012 № 107н (ред. от 01.02.2018) «О порядке использования вспомогательных репродуктивных технологий, противопоказаниях и ограничениях к их применению» ${ }^{14}$. В части 7 ст. 55 Федерального закона «Об основах охраны здоровья граждан в РФ» установлены определенные требования к донорам половых клеток: возраст (18-35 лет), здоровье (физическое и психическое), прохождение медико-генетического обследования. Таким образом, законодательством России не предусмотрена возможность заключения договора о суррогатном материнстве для одиноких мужчин, желаю-

9 Борисова Т. Е. Указ. соч.

10 Елисеев В. С. Государственное регулирование аграрных отношений: правовое обеспечение и защита имущественного интереса субъектов сельского хозяйства : автореф. дис. ... д-ра юрид. наук. М., 2011. С. 13.

11 См. подробнее: Козловская А. Э. Правовые аспекты суррогатного материнства // Гражданское право. 2006. № 2. С. 28 ; Чаплыгин А. Н. Суррогатное материнство: To be or not to be? // Актуальные проблемы частноправового регулирования : материалы Всероссийской научной конференции молодых ученых. Самара, 2004. С. 386.

12 Чаплыгин А. Н. Указ. соч. С. 386.

13 Борисова Т. Е. Указ. соч.

14 Российская газета : спецвыпуск. 2013. 11 апр. № 78/1. 
щих иметь семью, ребенка, что, на наш взгляд, нарушает их права, поскольку является дискриминацией по половому признаку и нарушением ст. 19 Конституции Российской Федерации ${ }^{15}$.

По российскому законодательству спорным остается и вопрос о том, кто является матерью и отцом рожденного суррогатной матерью ребенка.

В мировом сообществе существует два основных подхода к правовому регулированию отношений по договору суррогатного материнства. В одних странах законодательно признается приоритет прав генетических родителей в отношении ребенка, рожденного суррогатной матерью (например, Белоруссия, Украина). В ряде других стран закреплен приоритет прав суррогатной матери, согласие которой требуется для записи генетических родителей в качестве родителей рожденного ребенка (Россия).

Так, в соответствии с ч. 4 ст. 51 СК РФ ${ }^{16}$, состоящие в браке лица, которые дали письменное согласие на имплантацию эмбриона другой женщине в целях его вынашивания, могут быть записаны родителями ребенка лишь с ее согласия. Более того, в соответствии с Федеральным законом от 15.11.1997 (в ред. от 03.07.2019) «Об актах гражданского состояния» ${ }^{17}$ «при государственной регистрации рождения ребенка по заявлению супругов... должен быть представлен документ, выданный медицинской организацией и подтверждающий факт получения согласия женщины, родившей ребенка (суррогатной матери), на запись указанных супругов родителями ребенка» (ч. 5 ст. 16). Как следствие - не защищены права генетических родителей и ребенка.

Следует отметить, что определение законодателем приоритета прав суррогатной матери над правами генетических родителей в отношении родившегося ребенка противоречит закрепленному в ст. 38 Конституции РФ принципу охраны семьи, материнства и детства. Внимание на это обращает и судья Конституционного Суда РФ С. Д. Князев: «...целью суррогатного материнства... является предоставление... возможности стать родителями своего генетического ребенка, в этой связи неминуемо возникает вопрос о том, насколько избранный законодателем вариант правового регулирования, снимающий, по мнению многих экспертов, в интересах детей даже потенциальную возможность споров по поводу прав на ребенка между суррогатной матерью и генетическими родителями, соответствует целевому предназначению института суррогатного материнства» ${ }^{18}$.

Законодательство Белоруссии и Украины решает эту проблему иным способом. В частности, согласно ст. 52 Кодекса Республики Беларусь о браке и семье ${ }^{19}$ родителями рожденного суррогатной матерью ребенка (детей) признаются женщина, с которой был заключен договор, и ее супруг без права оспаривания материнства и (или) отцовства (за исключением случаев наличия доказательств наступления беременности суррогатной матери не в результате применения вспомогательных репродуктивных технологий).

Не вызывает сомнений тот факт, что на сегодняшний день законодательством Беларуси (в от-

15 Конституция Российской Федерации (принята всенародным голосованием 12.12.1993) (с учетом поправок, внесенных Законами РФ о поправках к Конституции РФ от 30.12.2008 № 6-ФК3, от 30.12.2008 № 7-ФК3, от 05.02.2014 № 2-ФК3, от 21.07.2014 № 11-ФК3) // С3 РФ. 2014. № 31. Ст. 4398.

16 Семейный кодекс Российской Федерации от 29.12.1995 № 223-Ф3 (ред. от 29.05.2019) // С3 РФ. 1996. № 1. Ст. 16.

17 СЗ РФ. 1997. № 47. Ст. 5340.

18 Определение КС РФ от 15.05.2012 № 880-О «Об отказе в принятии к рассмотрению жалобы граждан Ч. П. и Ч. Ю. на нарушение их конституционных прав положениями п. 4 ст. 51 СК РФ и п. 5 ст. 16 Федерального закона “Об актах гражданского состояния"». Мнение судьи Конституционного Суда РФ С. Д. Князева // Доступ из СПС «КонсультантПлюс» (дата обращения: 16.09.2019).

19 Кодекс Республики Беларусь о браке и семье от 09.07.1999 № 278-3 (ред. от 17.07.2018) // Национальный правовой интернет-портал Республики Беларусь. URL: http://www.pravo.by/document/?guid=3961\&p0= НК9900278 (дата обращения: 16.09.2019). 
личие от РФ) достаточно подробно регламентированы вопросы суррогатного материнства, включая требования к оформлению договора суррогатного материнства. С 19 июля 2012 г. вступил в силу Закон РБ «О вспомогательных репродуктивных технологиях ${ }^{20}$ (далее - Закон РБ о ВРТ), в который 18 июня 2019 г. были внесены изменения ${ }^{21}$ в целях совершенствования законодательства в данной сфере, в частности касающиеся возрастных ограничений и расширяющие возможности людей более старшего возраста принимать участие в репродуктивных программах, а также возможности зачатия ребенка от анонимного донора для женщин, не состоящих в браке.

В Законе РБ о ВРТ определены основные понятия в сфере суррогатного материнства (генетическая мать, суррогатная мать, суррогатное материнство и др.), а также условия и порядок его применения; регламентирован договор суррогатного материнства, определены его существенные условия; установлены требования к суррогатной матери. В статье 1 названного Закона четко определено, что ребенок, выношенный и рожденный женщиной по договору суррогатного материнства, не является носителем ее генотипа, что предотвращает любые последующие споры о генетической принадлежности такого ребенка. В этой же статье говорится о том, что рожденный таким способом ребенок является носителем генотипа женщины, с участием половой клетки которой был образован эмбрион, перенесенный в дальнейшем в матку суррогатной матери. Суррогатное материнство применяется на основе договора о суррогатном материнстве, который является возмездным, за исключением случаев предоставления услуг по суррогатному материнству родственниками (ст. 20-21 Закона РБ о ВРТ). Договор должен быть заключен в письменной форме лицами, состоящими в браке, и нотариально удостоверен.
При этом необходимо получить письменное согласие супругов этих лиц. Что касается сторон договора, то, согласно ст. 21 Закона РБ о ВРТ, таковыми являются суррогатная мать - с одной стороны и генетическая мать или женщина, воспользовавшаяся донорской яйцеклеткой, с другой.

По российскому законодательству второй стороной по договору суррогатного материнства могут быть либо потенциальные родители, половые клетки которых были использованы для оплодотворения, либо одинокая женщина, для которых вынашивание и рождение ребенка невозможно по медицинским показаниям (ч. 9 ст. 55 Федерального закона «Об основах охраны здоровья граждан в РФ»).

Как и по законодательству РФ, в Беларуси суррогатная мать не может являться одновременно и донором яйцеклетки. Что касается требований к суррогатной матери, то как и в России, законодательство Беларуси устанавливает требования к ее возрасту (от 20 до 35 лет включительно), закрепляет необходимость отсутствия медицинских противопоказаний, а также обязательное наличие ребенка. В России, помимо названных, обязательным требованием к суррогатной матери также является ее добровольное информированное согласие на медицинское вмешательство, истребованное в письменной форме.

Однако, в отличие от РФ, где суррогатной матерью может стать женщина, как не состоящая, так и состоящая в браке (при условии наличия письменного согласия супруга), по законодательству Беларуси обязательным требованием к суррогатной матери по общему правилу является необходимость ее состояния в браке. Вместе с тем белорусским законодательством установлены некоторые исключения, позволяющие женщине более старшего возраста (до 49 лет включительно) стать суррогатной мате-

20 Закон Республики Беларусь от 07.01.2012 № 341-3 «О вспомогательных репродуктивных технологиях» // Законодательство Республики Беларусь. URL: http://pravo.newsby.org/belarus/zakon0/z175.htm (дата обращения: 16.09.2019).

21 Закон Республики Беларусь от 18.06.2019 № 200-3 «Об изменении Закона Республики Беларусь “О вспомогательных репродуктивных технологиях" // Национальный правовой интернет-портал Республики Беларусь. URL: http://pravo.by/upload/docs/op/H11900200_1561496400.pdf (дата обращения: 16.09.2019). 
рью, если она является родственницей генетической матери или женщины, воспользовавшейся донорской яйцеклеткой, или их супругов и либо состоит в браке и имеет несовершеннолетнего ребенка, либо имеет совершеннолетнего и не имеет несовершеннолетнего ребенка.

Вместе с тем законодательство Беларуси более заботится об интересах и правах будущего ребенка и его генетических родителей, устанавливая расширенный перечень обязательных требований к суррогатной матери в ст. 22 Закона РБ о ВРТ, в которой назван исчерпывающий перечень случаев, когда женщина не может быть суррогатной матерью. Эти случаи связаны с признанным в судебном порядке ограничением ее дееспособности, ограничением и лишением родительских прав, отстранением от обязанностей опекуна или попечителя, наличием отмененного судом по ее вине статуса усыновителя (удочерителя), осуждением за совершение тяжкого преступления, а также наличием обвинения или подозрения по уголовному делу.

Еще одной важной отличительной чертой белорусского законодательства в исследуемой сфере является нормативное закрепление существенных условий договора о суррогатном материнстве, к которым отнесены в том числе обязанности сторон договора по передаче и принятию рожденного ребенка (детей) от суррогатной к генетической матери или женщине, воспользовавшейся донорской яйцеклеткой. К существенным отнесены также условие о сроке передачи и принятия ребенка (детей); об оказании услуги по его вынашиванию и рождению; о количестве переносимых в матку суррогатной матери эмбрионов; о медицинских организациях, в которых будут проведены все планируемые медицинские вмешательства от изъятия и соединения половых клеток до родов; об обязанности суррогатной матери выполнять врачебные предписания и предоставлять генетическим родителям информацию о состоянии здоровья (своего и ребенка) и месте проживания; о стоимости предоставляемой услуги (исключение - безвозмездный договор); о порядке «возмещения расходов на медицинское обслуживание, питание, проживание суррогатной матери в период вынашивания, родов и в послеродовой период» (ст. 21 Закона РБ о ВРТ).

Следует отметить, что в целом отношения суррогатного материнства довольно подробно регламентированы законодательством Республики Беларусь, в котором установлены и порядок заключения договора суррогатного материнства, и его существенные условия, и требования к форме, чего нельзя сказать о законодательстве Российской Федерации. Белорусское законодательство, в отличие от российского, содержит более эффективные механизмы защиты прав и законных интересов как будущего ребенка, так и сторон договора суррогатного материнства, детально регламентируя последний и устанавливая права и обязанности каждой из его сторон. Более того, на законодательном уровне закреплен возмездный характер договора суррогатного материнства. Исключение составляют лишь случаи предоставления услуг по суррогатному материнству родственниками (ст. 21 Закона РБ о ВРТ). В законодательстве Российской Федерации все эти вопросы до настоящего времени остаются неурегулированными.

В семейном законодательстве России не содержится даже определения суррогатного материнства, оно дается лишь в Федеральном законе «Об основах охраны здоровья граждан в РФ». На наш взгляд, необходимо дополнить СК РФ нормой, регулирующей договор суррогатного материнства, а также на законодательном уровне регламентировать права генетических родителей в отношении рожденного суррогатной матерью ребенка. В частности, следует закрепить в законе норму о том, что потенциальные родители, заключившие с суррогатной матерью договор суррогатного материнства, являются матерью и отцом рожденного суррогатной матерью ребенка. В статье 52 Кодекса Республики Беларусь о браке и семье четко определено, что суррогатная мать не признается матерью рожденного ребенка, что исключает возникновение на практике споров относительно происхождения ребенка, рожденного суррогатной матерью, которые в последнее время нередки в России 22 .

22 См., например: определение КС РФ от 15.05.2012 № 880-О. 
При дополнении российского законодательства (посредством принятия отдельного закона о суррогатном материнстве либо внесения изменений и дополнений в действующие законы) необходимо решить следующие вопросы:

- четко закрепить, что родителями рожденного суррогатной матерью ребенка являются его генетические родители, а не суррогатная мать;

- кроме возраста, наличия собственного ребенка или состояния здоровья, необходимо установить ряд ограничений по отношению к суррогатной матери немедицинского характера (судимость, лишение родительских прав, наличие наследственных болезней, употребление алкоголя и т.д.);
- необходимо усилить механизм гарантий прав добросовестных генетических родителей (например, предусмотреть штрафные санкции для суррогатной матери, отказавшейся от исполнения договора);

- необходимо гарантировать права и другой стороны договора - суррогатной матери, в частности нормативно ответив на вопрос о том, имеет ли право суррогатная мать на причитавшееся ей вознаграждение (или его часть), если ребенок оказался мертворожденным не по ее вине;

- следует урегулировать в федеральном законе вопрос о том, допустимо ли установление предельного количества раз осуществления функций суррогатной матери (или это станет коммерческой деятельностью).

\section{БИБЛИОГРАФИЯ}

1. Борисова Т. Е. Суррогатное материнство в РФ: проблемы теории и практики : монография. - М., 2012.

2. Елисеев В. С. Государственное регулирование аграрных отношений: правовое обеспечение и защита имущественного интереса субъектов сельского хозяйства : автореф. дис. ... д-ра юрид. наук. - М., 2011. $-481 \mathrm{c}$.

3. Звенигородская Н. Ф. Семейно-правовые сделки: проблемы классификации // Вестник Омского университета. Серия : Право. - 2011. - № 4. - С. 79-87.

4. Козловская А. Э. Правовые аспекты суррогатного материнства // Гражданское право. - 2006. - № 2. С. 27-29.

5. Краснова Т. В. Основания возникновения семейных правоотношений // Современное состояние российского законодательства: проблемы и пути совершенствования : тезисы докладов междунар. науч.-практ. конф. (г. Пермь, 23 октября 2009 г.). - Пермь, 2009.

6. Малиновская Е. Г. Правовое регулирование суррогатного материнства в Российской Федерации и в Республике Беларусь // Семейное и жилищное право. - 2007. - № 2. - С. 25-29.

7. Митрякова Е. С. Правовое регулирование суррогатного материнства в России : дис. ... канд. юрид. наук. - Тюмень, 2007. - 175 с.

8. Чаплыгин А. Н. Суррогатное материнство: To be or not to be? // Актуальные проблемы частноправового регулирования : материалы Всероссийской научной конференции молодых ученых. - Самара, 2004.

9. Чашкова С. Ю. Система договорных обязательств в российском семейном праве : автореф. дис. ... канд. юрид. наук. - М., 2004. - 197 с.

Материал поступил в редакцию 19 сентября 2019 г. 


\section{REFERENCES (TRANSLITERATION)}

1. Borisova T. E. Surrogatnoe materinstvo v RF: problemy teorii i praktiki : monografiya. - M., 2012.

2. Eliseev V. S. Gosudarstvennoe regulirovanie agrarnyx otnoshenij: pravovoe obespechenie i zashhita imushhestvennogo interesa subektov selskogo xozyajstva : avtoref. dis. ... d-ra yurid. nauk. - M., 2011. $481 \mathrm{~s}$.

3. Zvenigorodskaya N. F. Semejno-pravovye sdelki: problemy klassifikacii // Vestnik Omskogo universiteta. Seriya : Pravo. - 2011. - № 4. - S. 79-87.

4. Kozlovskaya A. E. Pravovye aspekty surrogatnogo materinstva // Grazhdanskoe pravo. — 2006. — № 2. — S. 27-29.

5. Krasnova T. V. Osnovaniya vozniknoveniya semejnyx pravootnoshenij // Sovremennoe sostoyanie rossijskogo zakonodatelstva: problemy i puti sovershenstvovaniya : tezisy dokladov mezhdunar. nauch.-prakt. konf. (g. Perm, 23 oktyabrya 2009 g.). - Perm, 2009.

6. Malinovskaya E. G. Pravovoe regulirovanie surrogatnogo materinstva v Rossijskoj Federacii i v Respublike Belarus // Semejnoe i zhilishhnoe pravo. - 2007. - № 2. - S. 25-29.

7. Mitryakova E. S. Pravovoe regulirovanie surrogatnogo materinstva v Rossii : dis. ... kand. yurid. nauk. Tyumen, 2007. $-175 \mathrm{~s}$.

8. Chaplygin A. N. Surrogatnoe materinstvo: To be or not to be? // Aktualnye problemy chastnopravovogo regulirovaniya : materialy Vserossijskoj nauchnoj konferencii molodyx uchenyx. - Samara, 2004.

9. Chashkova S. Yu. Sistema dogovornyx obyazatelstv v rossijskom semejnom prave : avtoref. dis. ... kand. yurid. nauk. - M., 2004. - $197 \mathrm{~s}$. 